\title{
Hypnotic susceptibility and affective states in bipolar I and II disorders
}

\author{
Bingren Zhang, Jiawei Wang, Qisha Zhu, Guorong Ma, Chanchan Shen, Hongying Fan and Wei Wang*
}

\begin{abstract}
Background: Highly hypnotizable individuals have impaired executive function, elevated motor impulsivity and increased emotional sensitivity, which are sometimes found in bipolar disorder patients. It is then reasonable to assume that certain aspects of hypnotic susceptibility differ with the types of bipolar disorder.

Methods: The Stanford Hypnotic Susceptibility Scale: Form C (SHSS:C) test, the Mood Disorder Questionnaire (MDQ), the Hypomanic Checklist-32 (HCL-32) and the Plutchick-van Praag Depression Inventory (PVP) were applied to 62 patients with bipolar I disorder, 33 bipolar II disorder, and 120 healthy volunteers.

Results: The passing rate of the SHSS:C 'Moving hands apart' item was higher in bipolar I patients than in controls, whereas for 'Mosquito hallucination' the rate was lower. Bipolar I and II patients scored significantly higher on MDQ, HCL-32 and PVP scales than controls. The passing rates of 'Mosquito hallucination' in controls, 'Arm rigidity' in bipolar I, and 'Age regression' in bipolar II predicted the respective MDQ scores.

Conclusion: In contrast to cognitive suggestions, bipolar I patients followed motor suggestions more often under hypnosis. Furthermore, both bipolar disorder patients and healthy volunteers demonstrated associations between mania levels and certain hypnotic susceptibility features. Our study aids in better understanding the altered conscious states in bipolar disorders, and encourages the use of related psychotherapy for these patients.
\end{abstract}

Keywords: Bipolar I and II disorders, Depression, Hypomania, Hypnotic susceptibility, Mania

\section{Background}

Hypnotic susceptibility (or hypnotizability) is the ability of an individual to experience suggested alterations in physiology, sensations, emotions, thoughts, or behaviors during hypnosis [1], which is relatively stable throughout life [2]. Literature shows that hypnotic susceptibility is an important factor in cognitive hypnotherapy, though it cannot accurately predict treatment outcome [3]. However, hypno-psychotherapy is recommended in the treatment of emotional disorders, as it can reduce patients' reactivity to internal or external triggers [4]. Studies have shown that people with personality traits such as extraversion [5], absorption [6], fantasy proneness [7], and openness to experience [8], are more easily hypnotized. Interestingly, high hypnotizables have been reported to be more impulsive than the lows, and often display nonplanning and motor impulsivity [9]. Additionally, they

\footnotetext{
* Correspondence: drwangwei@zju.edu.cn; wangmufan@msn.com Department of Clinical Psychology and Psychiatry/ School of Public Health, Zhejiang University College of Medicine, Hangzhou, Zhejiang 310058, China
}

have been reported to experience more emotional feelings [10], empathy [11], and emotional contagion, as well as poses a heightened ability to access affective events in a nonhypnotic context [12].

Some studies have shown that high hypnotizables experience more vivid mental-imagery [13, 14], although these results are not always reproducible [15]. Other studies have indicated that high hypnotizables have more intrusive thoughts [16], which require a stronger intervention on the individual's psyche to produce relevant imagery $[17,18]$. Interestingly, clinical disorders such as posttraumatic stress disorder [19] and dissociative disorder [20], which have emotional and intrusive symptoms, often display high hypnotizability. Mechanisms behind these phenomena are believed to fit into the dissociated-control theory, which explains that hypnosis causes a release of lower-level cognitive systems from the organization and control of higher-level integrating processes [21]. In this case, the release of lower-level 
activities might be linked with the impaired executive function of the frontal lobe in these pathologies [22].

Bipolar disorders often present with succeeding episodes of mania, depression, euthymia [23], and severe impairments in executive functions [24-27], including inhibitory control [28-30]. Bipolar I (BD I) and II (BD II) are the main types of bipolar disorders, the former having a higher prevalence of reckless activity, distractibility, psychomotor agitation, irritable mood and increased self-esteem [31], whereas the latter is characterized by a more chronic depressive course [32], often overactivated in goal-directed tasks [33]. Both BD I and BD II patients are impulsive [34], however, BD I is also characterized by higher levels of impulsive sensation seeking and borderline traits $[35,36]$, whereas BD II by higher neuroticism [37]. As these different affective or personality traits are associated with hypnotizability (for instance, the proven link between neuroticism and hypnotizability [38]), different types of bipolar disorder may have different hypnotic characteristics.

Both BD I and BD II patients have impaired executive functions [24] and such dysfunctions are associated with hypnotizability [15], thus, these patients might seldom experience vivid imagery or other forms of cognitive dissociation during hypnosis $[13,14]$. Instead, both types of patients, particularly those with BD I, have insufficient metacognition [39] and high motor impulsivity [31, 34]. Studies have shown that these characteristics cause passive movements in individuals during hypnosis $[9,15,40]$, manifested by increased physical dissociation and responsiveness to motor suggestions [41].

In the present study, hypnotic susceptibility of both BD I and BD II patients was tested. We used a widely-accepted tool, namely, the Stanford Hypnotic Susceptibility Scale: Form C (SHSS:C) [41], to measure responsiveness to hypnotic suggestions, as well as the Mood Disorder Questionnaire (MDQ) [42], the Hypomania Checklist-32 (HCL-32) [43], and the Plutchik-van Praag Depression Inventory (PVP) [44], to measure mania, hypomania and depression levels in our participants respectively. Based on previous findings, we hypothesized that (1) patients with bipolar disorder, especially BD I, are more easily motor- instead of cognitive-hypnotized and that (2) the ongoing affective states, measured by MDQ, HCL-32 and PVP, in patients are associated with their hypnotic susceptibility.

\section{Methods}

\section{Participants}

Overall, 62 patients with BD I (32 men and 30 women; aged 19.95 years \pm 1.80 S.D., range $18-27$ years), 33 BD II (10 men and 23 women; aged $19.67 \pm 1.76$, range 18-26), and 120 university students as healthy volunteers (controls; 45 men and 75 women; aged $20.53 \pm 2.44$, range 18-32) were enrolled in the study. All participants were right-handed, without previous hypnosis experience. A semi-structured interview was performed with each healthy participant to ensure that they were not suffering from any psychiatric or neurological problem. All patients were diagnosed by an experienced psychiatrist (WW), according to the Diagnostic and Statistical Manual of Mental Disorders (DSM-5) criteria [23]. Recent computer tomography or magnetic resonance imaging scans conducted on patients displayed normal skulls, midlines, and parenchyma, including cerebella and brain stems. The patients were not currently requiring in-patient care, and were not suffering from dissociative identity disorder, personality disorders, posttraumatic stress disorder, drug/ alcohol abuse or schizophrenia. Moreover, participants declared to be free from any drug or alcohol for at least $72 \mathrm{~h}$ prior to the test.

The participants were submitted to the SHSS:C test, and were then asked to complete the MDQ, HCL-32, and PVP scales in a quiet room.

\section{Hypnotic susceptibility test}

The SHSS:C [41] is a standardized 12-item measurement of an individual's response to suggestions following a hypnotic induction, in which items are offered in order of increasing difficulty. As a measure of heterogeneous characteristics, it consists of motor suggestions, which are direct calls for performance, such as 'Hand-lowering', involving the lowering of an outstretched hand while imagining holding a heavy weight; challenge suggestions, during which participants experience loss of arbitrary motor control, such as 'Arm rigidity' and 'Arm immobilization'; and cognitive suggestions, leading to changes in perception, memory, and cognition, such as 'Mosquito hallucination', 'Posthypnotic amnesia', 'Age regression', etc. This method was demonstrated to be valid $[45,46]$ and reliable [46] in several cultures, including Chinese.

Individual SHSS:C tests were performed under the guidance of one of the authors, who was blind to the grouping information of the participants. The procedure lasted approximately $45 \mathrm{~min}$, starting with a unified interpretational set and eye-closure induction. Each suggestion carried out successfully, as judged by the hypnotist according to objective criteria, was noted as passed and counted as one point. Considering the heterogeneity of the measure, both the passing rate of all 12 items and the rate of each item were calculated, according to the percentage of participants who had passed the item(s).

\section{Questionnaire measures}

A. The Mood Disorder Questionnaire (MDQ).

The MDQ consists of three parts [42], including 13 forced-choice (yes or no) questions to assess the presence of symptoms and behaviors related to mania or 
hypomania, one question to determine whether two or more symptoms have been experienced at the same time, and one question to determine the extent to which symptoms have caused functional impairment, based on a scale ranging from "no problems" to "serious problems". The MDQ internal reliability was .79 and was demonstrated to be valid in a sample of Chinese individuals [47].

B. The Hypomania Checklist-32 (HCL-32).

The HCL-32 is a self-assessment instrument comprising 32 items for detecting hypomanic symptoms [44]. Individuals were instructed to answer forced-choice (yes or no) questions about emotions, thoughts, or behaviors, and to answer questions regarding their duration, impact on family, social and work life, or reactions elicited from peers. The HLC-32 internal reliability was .88 and was demonstrated to be valid in a sample of Chinese individuals [48].

C. The Plutchik-van Praag Depression Inventory (PVP).

The PVP consists of 34 items [44], each with three scale points $(0,1,2)$ corresponding to increasing depressive tendencies. Subjects have "possible depression" if they score between 20 and 25, or "depression" if they score above 25. The PVP is a valid measure consistent with other similar tools [49], and its internal reliability was .94 in a sample of Chinese individuals [50].

\section{Statistical analysis}

In the three groups, mean age and mean MDQ, HCL-32 and PVP scores were analyzed by one-way ANOVA. Once a group effect was detected, a post-hoc Bonferroni test was used. The gender distribution and the total scores of SHSS:C in the three groups were analyzed by Chi-Square test. Considering that each SHSS:C item measures a different aspect of hyponotizability [41], the passing rates of each item were also computed by ChiSquare test. Once a group effect was detected, a posthoc Dunn's test was used, and the Bonferroni correction was used to adjust the multiple analyses. Based on a previous study [51], we applied the multiple linear regression analysis (backward method) to explore the relationships between SHSS:C passing rates, MDQ, HCL-32 and PVP scales, considering the affective states as potential predictors for the passing rates. The alpha level of significance $(p)$ was set at 05 .

\section{Results}

No significant difference was found among the three groups regarding either age $(\mathrm{F}[2,212]=2.65$, mean square effect $(\mathrm{MSE})=12.62, p=.07)$ or gender $\left(\chi^{2}=5.03\right.$, $d f=2, p=.08)$. The internal reliabilities of MDQ, HCL-32 and PVP in the current sample were $.78, .87, .94$ respectively. The mean MDQ scores were significantly different among the three groups $(\mathrm{F}[2,212]=134.22, \mathrm{MSE}=647.29$, $\left.p<.01, \eta^{2}=.56\right)$, with BD I patients scoring significantly higher than BD II patients and controls $(p s<.01)$. The mean HCL-32 scores were significantly different among the three groups $(\mathrm{F}[2,212]=110.44, \mathrm{MSE}=1263.65$, $p<.01, \eta^{2}=.51$ ), with BD I and BD II patients scoring significantly higher than controls, and BD I higher than BD II ( $p$ s $<.01)$. The mean PVP scores were also significantly different among the three groups ( $\mathrm{F}[2,212]=99.86, p<.01$, MSE $=3149.69, \eta^{2}=.49$ ), with BD II patients scoring significantly higher than both BD I and controls, and BD I higher than controls $(p s<.01)$ (Table 1$)$.

The internal reliability of SHSS:C in the current sample was .63 $(N=215)$. There were no significant differences in the total score of SHSS:C between the three groups $\left(x^{2}=0.60, d f=2, p=.74\right)$. By contrast, when comparing the passing rates of individual SHSS:C items, there were significant group effects on 'Moving hands apart' $\left(\chi^{2}=6.68, d f=2, p=.04, \eta^{2}=.19\right)$ and on 'Mosquito hallucination' $\left(\chi^{2}=7.56, d f=2, p=.02\right.$, $\eta^{2}=.22$ ). Post-hoc test detected that BD I patients passed the item 'Moving hands apart' significantly more often (adjusted $p=.03, \mathrm{OR}=0.31$ ), and passed the item 'Mosquito hallucination' less often (adjusted $p=.03$, $\mathrm{OR}=2.28$ ) than controls (see Table 2). No other significant differences among items were found between groups. Regarding the associations between hypnotic susceptibility and affective states, the passing number of SHSS:C 'Mosquito hallucination' (beta, .24; B, 1.39; standardized error, .52) in controls (adjusted $\mathrm{R}^{2}, .05$ ), 'Arm rigidity' (beta, .35; B, 1.02; standardized error, .36) in BD I (adjusted $\mathrm{R}^{2}$, .11), and 'Age regression' (beta, .35, B, 1.70; standardized error, .82 ) in BD II (adjusted $\mathrm{R}^{2}, .09$ ) significantly predicted the MDQ scores.

\section{Discussion}

To the best of our knowledge, this is the first study to test hypnotic susceptibility in patients with bipolar disorder. Both BD I and BD II patients displayed more pronounced emotional problems, as previously reported [35, 36, 48]. No differences were found between groups among SHSS:C total scores, however, when regarding the individual items, BD I patients possessed higher passing rates of SHSS:C 'Moving hands apart' and lower of 'Mosquito hallucination'. Furthermore, certain SHSS:C items were associated with the mania levels of both patients and healthy volunteers.

The 'Moving hands apart' is a simple motor suggestion [41], and the higher passing rate recorded in BD I patients suggested that it was easier for these patients to engage in less cognitive-demanding tasks. With impaired executive function and metacognition $[39,52]$ and high levels of impulsivity [34], these patients moved impulsively when hypnotic instructions were given $[9,40]$. Moreover, the impaired executive function and metacognition might underlie the lower passing rate of 
Table 1 Scale scores (mean \pm S.D.) of the Mood Disorder Questionnaire, the Hypomania Checklist-32, and the Plutchik-van Praag Depression Inventory in healthy volunteers (controls, $n=120)$, and patients with bipolar I (BD I, $n=62)$ and II (BD II, $n=33)$ disorders

\begin{tabular}{llll}
\hline & Controls & BD I & BD II \\
\hline Mood Disorder Questionnaire & $4.47 \pm 2.66$ & $9.84 \pm 1.27^{*}$ & $4.24 \pm 1.62^{\#}$ \\
Hypomania Checklist-32 & $15.09 \pm 3.77$ & $22.94 \pm 1.77^{*}$ & $18.42 \pm 4.13^{* \#}$, \\
Plutchik-van Praag Depression Inventory & $8.48 \pm 4.89$ & $12.74 \pm 7.14^{*}$ & $24.03 \pm 4.79^{*}$, \\
\hline
\end{tabular}

${ }^{*}, p<.05$ vs. controls; ${ }^{*}, p<.05$ vs. BD I

'Mosquito hallucination' in BD I group. Indeed, this hypnotic item is a positive hallucination, and its induction requires greater utilization of fantasy and imagery [53], which strongly demands the involvement of executive functions $[54,55]$. Therefore, their abnormal hypnotizability fits into the dissociated-control theory [21], and is explainable by the impaired frontal lobe executive function reported in BD I patients [22], partly accounting for their distractibility, psychomotor agitation [31] and problem-solving difficulty [56].

A common relationship between mania symptoms awake and altered states of consciousness induced by hypnosis [57] was replicated in both BD I and BD II groups, which were supported by the finding that patients with bipolar disorder display higher mood instability and higher levels of intrusive prospective imagery [18]. Specifically, 'Arm rigidity', an item of physical dissociation, was associated with the MDQ score in BD I patients, indicating that the drive of the behavioral activation system was higher and was associated with mania in this disorder [58]. 'Age regression', an item of consciousness dissociation, was associated with the MDQ score in BD II patients, consistent with the findings of pronounced childhood trauma and related dissociative symptoms, and the manic-related anxiety characteristic to this disorder [59, 60]. 'Mosquito hallucination', often a manifestation of irritability, was associated with the MDQ score in healthy volunteers, which was partly in line with that the auditory hallucinations were regularly seen in bipolar disorder patients, especially during their manic episodes $[61,62]$.

However, certain limitations of the present study should be considered, for instance, the relatively small sample size, as well as the failure to record normal and disordered personality traits of the participants. The lower adjusted $\mathrm{R}^{2} \mathrm{~S}$ in our study also imply that there were other factors contributing to the manic expressions in bipolar disorders. Nevertheless, we have found higher motor- but lower cognitive-suggestions under hypnosis in BD I patients, and mania levels were associated with different hypnotic susceptibility features in all three groups.

\section{Conclusion}

BD I patients followed motor suggestions more often, unlike cognitive suggestions, under hypnosis, while both bipolar disorder patients and healthy volunteers demonstrated an association between mania levels and certain hypnotic susceptibility features. Our findings contribute to the understanding of emotional, cognitive and behavioral alterations in bipolar disorder patients, and encourage the incorporation of related psychotherapy in their treatment.

Table 2 Numbers of participants passed (passing rate of) the items of the Stanford Hypnotic Susceptibility Scale: Form C in healthy volunteers (controls, $n=120)$, and patients with bipolar I (BD I, $n=62)$ and II (BD II, $n=33)$ disorders

\begin{tabular}{|c|c|c|c|c|c|c|}
\hline & Controls & $\mathrm{BD} 1$ & $\mathrm{BD} \|$ & $x^{2}(d f: 2)$ & $p$ & $\eta^{2}$ \\
\hline Hand lowering & 97 (80.8\%) & $54(87.1 \%)$ & $28(84.8 \%)$ & 1.22 & .55 & .03 \\
\hline Moving hands apart & 89 (74.2\%) & $56(90.3 \%) a$ & $25(75.8 \%)$ & 6.68 & .04 & .19 \\
\hline Mosquito hallucination & 85 (70.8\%) & $32(51.6 \%) a$ & $18(54.5 \%)$ & 7.56 & .02 & .22 \\
\hline Taste hallucination & 91 (75.8\%) & 49 (79.0\%) & $27(81.8 \%)$ & 0.62 & .73 & .02 \\
\hline Arm rigidity & $83(69.2 \%)$ & $47(75.8 \%)$ & $26(78.8 \%)$ & 1.66 & .44 & .05 \\
\hline Dream & 46 (38.3\%) & $24(38.7 \%)$ & 15 (45.5\%) & 0.55 & .76 & .02 \\
\hline Age regression & $104(86.7 \%)$ & 52 (83.9\%) & 29 (87.9\%) & 0.11 & .95 & $<.01$ \\
\hline Arm immobilization & 65 (54.2\%) & 37 (59.7\%) & $23(67.7 \%)$ & 2.64 & .27 & .08 \\
\hline Anosmia to ammonia & 47 (39.2\%) & $22(35.5 \%)$ & $18(54.5 \%)$ & 3.05 & .22 & .10 \\
\hline Hallucinated voice & $18(15.0 \%)$ & $5(8.1 \%)$ & $3(9.1 \%)$ & 2.17 & .34 & .06 \\
\hline Negative visual hallucination & $48(40.0 \%)$ & 19 (30.6\%) & $10(31.3 \%)$ & 1.65 & .44 & .05 \\
\hline Posthypnotic amnesia & $18(15.0 \%)$ & $5(8.1 \%)$ & $6(18.2 \%)$ & 2.41 & .30 & .07 \\
\hline
\end{tabular}




\section{Abbreviations}

BD I: Bipolar I; BD II: Bipolar II; BD: Bipolar disorder; HCL-32: Hypomania Checklist-32; MDQ: Mood Disorder Questionnaire; PVP: Plutchik-van Praag Depression Inventory; SHSS:C: The Stanford Hypnotic Susceptibility Scale, Form C

\section{Acknowledgements}

The authors would like to thank all the patients and the healthy volunteers who took part in the sample collection and test.

\section{Funding}

Dr. W. Wang was sponsored by a grant from the Natural Science Foundation of China (No. 91132715).

\section{Availability of data and materials}

The datasets used and/or analyzed during the current study are available from the corresponding author on reasonable request.

\section{Authors' contributions}

Study concept and design: WW. Acquisition of data: BZ, JW, OZ, GM, CS, and HF. Analysis and interpretation of data: BZ, JW, CS, and WW. Draft written of the manuscript: BZ and WW. All authors read and approved the final manuscript.

\section{Ethics approval and consent to participate}

The study was approved by the ethics committee of Zhejiang University, and informed consent was obtained for experimentation with the participants.

\section{Consent for publication}

Not applicable.

\section{Competing interests}

The authors declare that they have no competing interests, and have followed correct procedures concerning treatment of humans in research.

\section{Publisher's Note}

Springer Nature remains neutral with regard to jurisdictional claims in published maps and institutional affiliations.

\section{Received: 11 May 2017 Accepted: 31 October 2017}

Published online: 09 November 2017

\section{References}

1. Elkins GR, Barabasz AF, Council JR, Spiegel D. Advancing research and practice: the revised APA division 30 definition of hypnosis. Int J Clin Exp Hypn. 2015:63:1-9.

2. Piccione C, Hilgard ER, Zimbardo PG. On the degree of stability of measured hypnotizability over a 25-year period. J Pers Soc Psychol. 1989;56:289-95.

3. Montgomery GH, Schnur JB, David D. The impact of hypnotic suggestibility in clinical care settings. Int J Clin Exp Hypn. 2011;59:294-309.

4. Alladin A, Amundson J. Cognitive hypnotherapy as a transdiagnostic protocol for emotional disorders. Int J Clin Exp Hypn. 2016;64:147-66.

5. Shor RE, Orne EC. Harvard group scale of hypnotic susceptibility. Palo Alto: Consulting Psychologists Press; 1962.

6. Zachariae R, Jorgensen MM, Christensen S. Hypnotizability and absorption in a Danish sample: testing the influence of context. Int J Clin Exp Hypn. 2000:48:306-14.

7. Rhue JW, Lynn SJ. Fantasy proneness, hypnotizability, and absorption-a re-examination: a brief communication. Int J Clin Exp Hypn. 1989:37:100-6.

8. Milling LS, Miller DS, Newsome DL, Necrason ES. Hypnotic responding and the five factor personality model: hypnotic analgesia and openness to experience. J Res Pers. 2013;47:128-31.

9. Ludwig VU, Stelzel C, Krutiak H, Prunkl CE, Steimke R, Paschke LM, et al. Impulsivity, self-control, and hypnotic suggestibility. Conscious Cogn. 2013;22:637-53

10. De Pascalis V. Psychophysiological correlates of hypnosis and hypnotic susceptibility. Int J Clin Exp Hypn. 1999;47:117-43.

11. Wickramasekera IE 2nd, Szlyk JP. Could empathy be a predictor of hypnotic ability? Int J Clin Exp Hypn. 2003;51:390-9.

12. Cardeña E, Terhune DB, Lööf A, Buratti S. Hypnotic experience is related to emotional contagion. Int J Clin Exp Hypn. 2009;57:33-46.
13. Shor RE, Orne MT, O'Connell DN. Psychological correlates of plateau hypnotizability in a special volunteer sample. J Pers Soc Psychol. 1966:3:80-95.

14. Dienes Z, Perner J. Executive control without conscious awareness: the cold control theory of hypnosis. Europhys Lett. 2014;108:37-48.

15. Terhune DB, Hedman LRA. Metacognition of agency is reduced in high hypnotic suggestibility. Cognition. 2017:168:176-81.

16. Bryant RA, Idey A. Intrusive thoughts and hypnotizability. Contemp Hypn. 2001;18:14-20

17. Carli G, Manzoni D, Santarcangelo EL. Hypnotizability-related integration of perception and action. Cogn Neuropsychol. 2008;25:1065-76.

18. Holmes EA, Deeprose C, Fairburn CG, Wallace-Hadrill SM, Bonsall MB, Geddes JR, et al. Mood stability versus mood instability in bipolar disorder: a possible role for emotional mental imagery. Behav Res Ther. 2011;49:707-13.

19. Spiegel D, Cardena E. New uses of hypnosis in the treatment of posttraumatic stress disorder. J Clin Psychiatry. 1990;51(Suppl):39-43.

20. Frischholz EJ, Lipman LS, Braun BG, Sachs RG. Psychopathology, hypnotizability, and dissociation. Am J Psychiatry. 1992;149:1521-5.

21. Woody E, Bowers K. A frontal assault on dissociated control. In: Lynn SJ, Rhue JW, editors. Dissociation: clinical and theoretical perspectives. New York: Guilford; 1994. p. 52-79.

22. Parris BA. The prefrontal cortex and suggestion: hypnosis vs. placebo effects. Front Psychol. 2016;7:415.

23. American Psychiatric Association. Diagnostic and Statistical Manual of Mental Disorders. 5th ed. Arlington, VA: American Psychiatric Association; 2013.

24. Antila M, Partonen T, Kieseppa T, Suvisaari J, Eerola M, Lonnqvist J, et al. Cognitive functioning of bipolar I patients and relatives from families with or without schizophrenia or schizoaffective disorder. J Affect Disord. 2009:116:70-9.

25. Hsiao YL, Wu YS, Wu JY, Hsu MH, Chen HC, Lee SY, et al. Neuropsychological functions in patients with bipolar I and bipolar || disorder. Bipolar Disord. 2009:11:547-54.

26. Dittmann S, Hennig-Fast K, Gerber S, Seemuller F, Riedel M, Emanuel SW, et al. Cognitive functioning in euthymic bipolar I and bipolar II patients. Bipolar Disord. 2008;10:877-87.

27. Glahn DC, Bearden CE, Barguil M, Barrett J, Reichenberg A, Bowden CL, et al. The neurocognitive signature of psychotic bipolar disorder. Biol Psychiatry. 2007:62:910-6.

28. Selva G, Salazar J, Balanza-Martinez V, Martinez-Aran A, Rubio C, Daban C, et al. Bipolar I patients with and without a history of psychotic symptoms: do they differ in their cognitive functioning? J Psychiatr Res. 2007:41:265-72

29. Stoddart SD, Craddock NJ, Jones LA. Differentiation of executive and attention impairments in affective illness. Psychol Med. 2007;37:1613-23.

30. Varga M, Magnusson A, Flekkoy K, Ronneberg U, Opjordsmoen S. Insight, symptoms and neurocognition in bipolar I patients. J Affect Disord. 2006;91:1-9.

31. Serretti A, Olgiati P. Profiles of "manic" symptoms in bipolar I, bipolar II and major depressive disorders. J Affect Disord. 2005:84:159-66.

32. Judd LL, Akiskal HS, Schettler PJ, Coryell W, Maser J, Rice JA, et al. The comparative clinical phenotype and long term longitudinal episode course of bipolar I and II: a clinical spectrum or distinct disorders? J Affect Disord. 2003:73:19-32.

33. Benazzi F. Testing new diagnostic criteria for hypomania. Ann Clin Psychiatry. 2007:19:99-104.

34. Swann AC, Dougherty DM, Pazzaglia PJ, Pham M, Moeller FG. Impulsivity: a link between bipolar disorder and substance abuse. Bipolar Disord. 2004;6:204-12.

35. Xu S, Gao Q, Ma L, Fan H, Mao H, Liu J, et al. The Zuckerman-Kuhlman personality questionnaire in bipolar I and II disorders: a preliminary report. Psychiatry Res. 2015;226:357-60.

36. Yao J, Xu Y, Qin Y, Liu J, Shen Y, Wang W, et al. Relationship between personality disorder functioning styles and the emotional states in bipolar I and II disorders. PLoS One 2015:10:e0117353.

37. Kim B, Lim JH, Kim SY, Joo YH. Comparative study of personality traits in patients with bipolar I and II disorder from the five-factor model perspective. Psychiatry Invest. 2012;9:347-53.

38. Stukat KG. Suggestibility: a factorial and experimental analysis. Stockholm: Almqvist and Wiksell; 1958

39. Popolo R, Smith E, Lysaker PH, Lestingi K, Cavallo F, Melchiorre L, et al. Metacognitive profiles in schizophrenia and bipolar disorder: comparisons with healthy controls and correlations with negative symptoms. Psychiatry Res. 2017:257:45-50. 
40. Oakley DA. Hypnosis as a tool in research: experimental psychopathology. Contemp Hypn. 2010;23:3-14.

41. Weitzenhoffer AM, Hilgard ER. Stanford hypnotic susceptibility scale: form C. Palo Alto: Consulting Psychologists Press; 1962.

42. Hirschfeld RM, Williams JB, Spitzer RL, Calabrese JR, Flynn L, Keck PE, et al. Development and validation of a screening instrument for bipolar spectrum disorder: the mood disorder questionnaire. Am J Psychiatry. 2000;157:1873-5.

43. Angst J, Adolfsson R, Benazzi F, Gamma A, Hantouche E, Meyer TD, et al. The HCL-32: towards a self-assessment tool for hypomanic symptoms in outpatients. J Affect Disord. 2005;88:217-33.

44. Plutchik R, van Praag HM. Interconvert ability of five self-report measures of depression. Psychiatry Res. 1987;22:243-56.

45. Hilgard ER. The Stanford hypnotic susceptibility scales as related to other measures of hypnotic responsiveness. Am J Clin Hyp. 1978;21:68-83.

46. Roark JB, Barabasz AF, Barabasz M, Lin-Roark IH. An investigation of Taiwanese norms for the Stanford hypnotic susceptibility scale: form C (mandarin Chinese translation). Int J Clin Exp Hypn. 2012;60:160-74.

47. Yang $H C$, Yuan $C M$, Liu TB, Li L, Peng HJ, Rong $H$, et al. Validity of the Chinese version mood disorder questionnaire (MDQ) and the optimal cut off screening bipolar disorders. Psychiatry Res. 2011;189:446-50.

48. Yang HC, Yuan CM, Liu TB, Li L, Peng HJ, Liao CP, et al. Validity of the 32-item hypomania checklist (HCL-32) in a clinical sample with mood disorders in China. BMC Psychiatry. 2011;11:84.

49. Dozois DJ. The psychometric characteristics of the Hamilton depression inventory. J Pers Assess. 2003;80:31-40.

50. Wang W, Cao M, Zhu S, Gu J, Liu J, Wang Y. Zuckerman-Kuhlman's personality questionnaire in patients with major depression. Soc Behav Pers. 2002;30:757-64.

51. Schrijvers DL, De Bruijn ER, Destoop M, Hulstijn W, Sabbe BG. The impact of perfectionism and anxiety traits on action monitoring in major depressive disorder. J Neural Transm. 2010;117:869-80.

52. Bentall RP. The illusion of reality: a review and integration of psychological research on hallucinations. Psychol Bull. 1990;107:82-95.

53. Barber TX. A comprehensive three-dimensional theory of hypnosis. Clinical hypnosis and self-regulation: cognitive-behavioral perspectives. Washington DC: American Psychological Association; 1999. p. 21-48.

54. Cojan Y, Piguet C, Vuilleumier P. What makes your brain suggestible? Hypnotizability is associated with differential brain activity during attention outside hypnosis. Neurolmage. 2015;117:367-74.

55. Hoeft F, Gabrieli JD, Whitfield-Gabrieli S, Haas BW, Bammer R, Menon V, et al. Functional brain basis of hypnotizability. Arch Gen Psychiatry. 2012;69:1064-72.

56. Xu G, Lin K, Rao D, Dang Y, Ouyang H, Guo Y, et al. Neuropsychological performance in bipolar I, bipolar II and unipolar depression patients: a longitudinal, naturalistic study. J Affect Disord. 2012;136:328-39.

57. Revonsuo A, Kallio S, Sikka P. What is an altered state of consciousness? Philos Psychol. 2009;22:187-204.

58. Fletcher K, Parker G, Manicavasagar V. Behavioral activation system (BAS) differences in bipolar I and II disorder. J Affect Disord. 2013;151:121-8.

59. Eryilmaz G, Kesebir S, Gül IG, Özten E, Karamustafalioğlu KO. Dissociative experiences in bipolar disorder II: are they related to childhood trauma and obsessive- compulsive symptoms? Arch Clin Psychiatry. 2015;42:38-40.

60. van den Berg B, Penninx BW, Zitman FG, Nolen WA. Manic symptoms in patients with depressive and/ or anxiety disorders. J Affect Disord. 2010;126:252-6.

61. Black DW, Nasrallah A. Hallucinations and delusions in 1715 patients with unipolar and bipolar affective disorders. Psychopathology. 1989;22:28-34

62. Bowman KM, Raymond AF. A statistical study of hallucinations in the manic-depressive psychosis. World Health Organ. 2007;67:111-21.

\section{Submit your next manuscript to BioMed Central and we will help you at every step:}

- We accept pre-submission inquiries

- Our selector tool helps you to find the most relevant journal

- We provide round the clock customer support

- Convenient online submission

- Thorough peer review

- Inclusion in PubMed and all major indexing services

- Maximum visibility for your research

Submit your manuscript at www.biomedcentral.com/submit
Biomed Central 